\title{
The Prediction Level of Self-Esteem on Humor Style and Positive-Negative Affect
}

\author{
Zumra Ozyesil \\ Faculty of Letters and Sciences, Department of Psychology, Istanbul Arel University, Istanbul, Turkey \\ Email: zumraozyesil@arel.edu.tr
}

Received May $24^{\text {th }}, 2012$; revised June $20^{\text {th }}, 2012$; accepted July $10^{\text {th }}, 2012$

\begin{abstract}
The aim of this study is to analyze if there are significant correlations among self-esteem, humor styles and positive-negative affection and if self esteem significantly predicts humor styles and positive-negative affection. A total of 440 under graduate students ( $77 \%$ female) chosen by random set sampling method participated in this study voluntarily. The mean age of the participants was 20.33 with a standard deviation of 1.73. Rosenberg Self-Esteem Scale, Humor Styles Questionnaire and The Positive and Negative Affect Schedule were employed in order to collect the data of the study. To analyze the data the Pearson moments correlation technique and multiple regression analysis were used. According to the findings of the study there were positive significant correlations between self-esteem and affiliative and self-enhancing humor styles, negative correlations between self esteem and aggressive and self defeating humor styles. Another finding of the study shows that there is a significant positive correlation between self-esteem and positive affection and a significant negative correlation between self-esteem and negative affect. Self-esteem significantly predicts the humor styles sub dimensions. Self-esteem explains $3.1 \%$ of the total variance in affiliative humor style $\left(R^{2}=.031, \beta=.176, p<.001\right), 5.7 \%$ of the total variance in self enhancing humor style $\left(R^{2}=.057, \beta=.239, p<.001\right), 1.1 \%$ of the total variance in aggressive humor style $\left(R^{2}=.011, \beta=-.107, p<.05\right), 4.1 \%$ of the total variance in self defeating humor style $\left(R^{2}=.041, \beta=\right.$ $-.208, p<.001)$. As a result of the analysis predicting the positive-negative affection; self-esteem explains $14.7 \%$ of the total variance in positive affect $\left(R^{2}=.147, \beta=.384, p<.001\right)$ and $4.2 \%$ of the total variance in negative affect $\left(R^{2}=-.042, \beta=-.204, p<.001\right)$.
\end{abstract}

Keywords: Humor Styles; Positive-Negative Affect; Self-Esteem; Prediction

\section{Introduction}

Self concept is a collection of the most important self perceptions, feelings, and thoughts on the basis of human personality (Öner, 1996). According to Chrzanowski (1981) in the broadest sense self esteem is the positive evaluation of the self, based on a good assessment his/her own abilities and powers. However, Coopersmith (1967) evaluates self-esteem as an important dimension of personality and a positive personality trait and also defines it as a degree of which an individual perceive him/herself efficient, important, competent and worthy.

Self-esteem is a concept associated with individuals' mental health and is an important part of one's overall well-being, it should in turn, be associated with other, general indicators of well-being such as positive and negative affection. Positive affection represents the extent to which an individual experiences pleasurable engagement with the environment whereas high negative affection epitomized by subjective distress and unpleasurable engagement (Watson \& Clark, 1984). Watson, Wiese, Vaidya and Tellegen (1999) state that positive affection and negative affection are defined by the activation of positively and negatively valence effects respectively (i.e. The lower ends of each dimension are typified by its absence).

On the other hand, the emotional responses to encountering challenge stressors include not only general positive emotions,

*This paper was presented at the 4th International Congress of Educational Research, İstanbul, Turkey, 4-7 May 2012. such as happiness and joy, but also pride which is an emotion that is specifically related to achievement and involves appraisal of one's worth as a person. Self-esteem which is a personal judgment of worthiness is related to positive affection.

Subjects high in self esteem, compared to subjects low in self-esteem were found to be more assertive, flexible and imaginative and were capable to find original solutions to the problems (Pervin, 1993). An individual with a humorous attitude is someone who understands the insufficiencies and shortcomings of life and fellow humans but also tolerates and forgives them rather than pokes fun at them. Self-esteem is known strongly relate to sense of humor (Kuiper \& Martin, 1998).

Humor Styles Questionnaire (HSQ) (Martin et al., 2003) has four dimensions-two adaptive and two maladaptive styles of humor, relating to different uses or functions of humor in everyday life focuses on the interpersonal and intrapsychic functions relevant to psychosocial well-being and various aspects of mental health. Two of these dimensions are considered to be conducive to psychosocial well-being and the other two are less benign and potentially even deleterious to well-being. The two adaptive styles are affiliative and self-enhancing humor and the two maladaptive humor styles are aggressive and self-defeating humor. Afilliative humor style reflects the tendency to share humor with others, telling jokes and amusing others and facilitating relationships. Self-enhancing humor style is to use humor as a coping strategy and emotion regulation in coping with stress and cheer oneself with up humor. Aggressive humor is tendency to use humor for the purpose of criticizing or ma- 
nipulating others, say funny things that are likely to hurt or alienate others. Aggressive humor style is excessively critical and ridiculing of one's self and attempts to amuse others by doing or saying funny things at one's own expense (Martin, 2003; Martin, Puhlik-Doris, Larsen, Gray \& Weir, 2003; Kazarian \& Martin, 2004). Affiliative and self-enhancing humor styles were positively related to self-esteem whereas self-defeating humor was negatively related to self-esteem (Saroglou \& Scariot, 2002). Consequently self-esteem origins starting in childhood and organized in adolescent may be a factor that effecting the life permanently (Satılmış \& Seber, 1989). This factor might have an effect on individuals' humor styles and positive-negative affection in their further life. The aim of this study is to analyze if there are significant correlations among selfesteem, humor styles and positive-negative affection and if self esteem significantly predicts humor styles and positive-negative affection. In consistent with the aim of the study, the answers of the given questions were looked for.

1) Is there a significant correlation between self-esteem and humor styles?

2) Does the self-esteem significantly predict the humor styles?

3) Is there significant correlation between self-esteem and positive-negative affect?

4) Does the self-esteem significantly predict positive-negative affect?

\section{Method}

\section{Participants}

A total of 440 under graduate students ( $77 \%$ female) chosen by random set sampling method participated in this study voluntarily. The mean age of the participants were 20.33 with a standart deviation of 1.73 .

\section{Measures}

Humor Styles Questionnaire (HSQ: Martin et al., 2003). The HSQ consists of a total of 32 self-report items assessing four different styles of humor, two of them are adaptive and two are maladaptive. Respondents indicate the degree to which they agree or disagree with each item using a seven-point Likert Scale. HSQ was adapted into Turkish by Yerlikaya (2003), The Cronbach alpha coefficient scores of HSQ were found .74 for affiliative humor, .78 for self-enhancing humor, .69 for aggressive humor and .67 for self defeating humor. The test- retest correlation coefficients of HSQ scale applied in two week intervals were, .88 for affiliative humor, .82 for self enhanceing humor, .85 for aggressive humor, and .85 for self defeating humor. In this study, the reliability of the Cronbach alpha coefficients of HSQ dimensions were .76 for affiliative humor, .76 for self enhancing, .54 for aggressive humor, and .71 for self defeating humor.

The Positive and Negative Affect Schedule (Watson, Clark, \& Tellegen, 1988) consists of two 10-item mood scales and was developed to provide brief measures of PA and NA. Respondents are asked to rate the extent to which they have experienced each particular emotion within a specified time period, with reference to a 5-point scale. The scale points are: 1, "very slightly or not at all"; 2, "a little"; 3, "moderately"; 4, "quite a bit" and 5, "very much". PANAS was adapted to Turkish by Gençöz (2000) and he found the same two factors as positive and negative. Reliability coefficients for each subscale of the PANAS were calculated as .83 and .86 and the test retest reliability were .40 and .54 , respectively.

Rosenberg Self-Esteem Scale (RSE) The RSE is a 10-item scale which is composed of 5 positive and 5 negative expressions. High scores on the RSE represent high levels of self-esteem. Turkish adaptation studies were carried out by Çuhadaroğlu (1986). A 10-item brief RSES rates the global self-worth of individuals on a 4-point Likert-type scale $(1=$ strongly disagree to $4=$ strongly agree). Cuhadaroğlu reported test-retest reliability coefficients of .71 over a 4-week period. For the construct validity, she found significant differences between the RSES scores of normal adolescents and neurotic $(p<.05)$ and psychotic $(p<.01)$ adolescents.

\section{Procedure}

Rosenberg Self-Esteem Scale, Humor Styles Questionnaire and The Positive and Negative Affect Schedule were employed in order to collect the data of the study. The data of the research was applied to the volunteer students during the class hours at the psychology department at a $30-40$ minutes period. In order to analyze the data the Pearson moments correlation technique and multiple regression analysis were used. The SPSS 10.0 packagewasused in theanalysis of thedata.

\section{Results}

As it is shown on Table $\mathbf{1}$ it was found that self-esteem was significantly positively related to affiliative and self-enhancing humor styles, negatively related to aggressive and self-defeating humor styles. Results indicating if self-esteem predicts the humor styles are given on Table 2.

Self-esteem significantly predicted the humor styles sub dimensions. Self-esteem explained $3.1 \%$ of the total variance in affiliative humor style, $5.7 \%$ of the total variance in self enhancing humor style, $1.1 \%$ of the total variance in aggressive humor style, $4.1 \%$ of the total variance in self defeating humor style (Table 3).

As it was shown, self-esteem was significantly positively related to positive affect and negatively related to negative affect. The results indicating if self-esteem predicts the positive-negative affect were given on Table 4 .

Table 1.

Correlations betwen self-esteem and humor styles.

\begin{tabular}{lcccc}
\hline & Affiliative & Self-Enhancing & Aggressive & Self-Defeating \\
\hline Self-Esteem & $.18^{* * *}$ & $.24^{* * *}$ & $-.11^{*}$ & $-.21^{* * *}$ \\
\hline Note: ${ }^{*} p<.05 ;{ }^{* * *} p<.001$. & & &
\end{tabular}

Table 2.

Explanations of humor styles (affiliative, self-enhancing, aggressive, self-defeating) by self-esteem.

\begin{tabular}{cccccc}
\hline Independent variable & $R$ & $R^{2}$ & $F$ & $\beta$ & $\mathrm{t}$ \\
\hline \multirow{3}{*}{ Self-esteem } & .176 & .031 & $13.995^{* * *}$ & .176 & $3.741^{* * *}$ \\
& .239 & .057 & $26.516^{* * *}$ & .239 & $5.149^{* * *}$ \\
& .107 & .011 & $5.062^{*}$ & -.107 & $-2.250^{*}$ \\
& .208 & .041 & $19.866^{* * *}$ & -.208 & $-4.457^{* * *}$ \\
\hline
\end{tabular}

Note: ${ }^{*} p<.05 ;{ }^{* * * *} p<.001$; Dependent variable: Humor styles (affiliative, self- enhancing, aggressive, self-defeating). 
Table 3.

Correlations between Self-esteem and positive-negative affect.

\begin{tabular}{lcc}
\hline & Positive Affect & Negative Affect \\
\hline Self-Esteem & $.38^{* * *}$ & $-.20^{* * *}$ \\
\hline
\end{tabular}

Note: ${ }^{* * *} p<.001$.

Table 4.

Explanations of positive-negative affect by self-esteem.

\begin{tabular}{cccccc}
\hline Independent variable & $R$ & $R^{2}$ & $F$ & $\beta$ & $\mathrm{t}$ \\
\hline \multirow{2}{*}{ Self-esteem } & .384 & .147 & $75.781^{* * *}$ & .384 & $8.705^{* * *}$ \\
& .204 & .042 & $19.022^{* * *}$ & -.204 & $4.361^{* * *}$ \\
\hline
\end{tabular}

Note: ${ }^{*} p<.05 ;{ }^{* *} p<.01 ;{ }^{* * *} p<.001$; Dependent variable: Positive-Negative affect.

Self-esteem significantly predicted the positive and negative affect. Self-esteem explained $14.7 \%$ of the total variance in positive affect and $4.2 \%$ of the total variance in negative affect.

\section{Discussion}

According to the findings of the study there were positive significant correlations between self-esteem and affiliative and self-enhancing humor styles, negative correlations between self esteem and aggressive and self defeating humor styles. Self esteem is a personal judgment of worthiness and it is a general personality characteristic (Pervin, 1993). Humor has been conceptualized in a variety of different ways and also it was seen as a personality trait (Martin, 2001) which have been defined as a dynamic organization inside the person and the characteristic pattern of thought, emotion and behavior which makes a person different or similar to others (Carver \& Scheier, 2000; Funder, 1997; Chamorro-Premuzic, 2008). It was found that self-esteem significantly predicts the humor styles sub dimensions. The affiliative humor style has a major effect on facilitating relationships and reduces interpersonal tensions. According to Kuiper \& McHale (2009) using affiliative humor style would form one behavioral strategy for increasing interpersonal closeness. Significantly higher levels of affiliative humor style predicted significantly higher levels of self esteem and greater use of self-enhancing humor style would result in increased self-esteem (Kuiper \& McHale, 2009). In a similar fashion selfenhancing humor style, using humor as a coping strategy and in emotion regulation may also contribute self-esteem by reducing the conflict when protecting the self. The two maladaptive humor styles, aggressive and self-defeating humor are negatively related to self esteem. Individuals using self-defeating humor style allow themselves to be the "butt" of jokes in the hopes of gaining others' approval and acceptance and is used to enhance relationships with others, but at the expense of positive feelings about self (Kuiper \& Leite, 2010). Using self defeating humor style these individuals may struggle to increase their self-esteem through relationships. Aggressive humor style is tendency to use humor for the purpose of criticizing or manipulating others and directed at others to enhance positive feelings about one's self which may be a result of lower levels of self-esteem. Kuiper and Martin's (1993) study, providing a direct empirical test of the proposed links between humor and a healthier, more positive self-concept, supports the results of the current study.

Another finding of the study shows that there was a signifycant positive correlation between self-esteem and positive af- fect and a significant negative correlation between self-esteem and negative affect. Individuals with lower self-esteem as they tend to have psychosomatic symptoms, anxiety and depression (Coopersmith, 1967) are expected to experience negative affecttion intensively and they are expected to have lower levels of positive affect. In addition, negative mood is characterized with such features as being unhappy, angry, hostile and scared, positive mood characterized with being energetic, strong, stable and careful (Watson et al., 1988; Gençöz, 2000). Intheirstudy Kuiperand Mchale (2009) stated that higher levels of affiliative humor predicted lower levels of depression and this finding supports the current study. Higher levels of self-enhancing humor predicted higher levels of social self-esteem and reduced depression. Higher levels of self-defeating humor predicted lower levels of social self-esteem and higher levels of depresssion.

According to the findings of the study, significant correlations were found between Self-esteem and humor styles and also positive-negative affect. The results of the study also show that individuals' self-esteem is affective both on humor styles and positive-negative affect. Depending on this, developing positive self-esteem can positively affect their well-being which might in turn enhance their interpersonal relationships and have contributions to healthy communications. The study also shows that supporting attitudes are important in developing the selfesteem which is started to be shaped by the first experiences.

\section{REFERENCES}

Carver, C. S., \& Scheier, M. F. (2000). Perspectives on personality (4th ed.). Boston: Allyn and Bacon.

Chamorro-Premuzic, T. (2008). Personality and individual differences. Maldon, MA: Blackwell Publishing.

Cooper, C. (2002). Individual differences. NY: Oxford University Press.

Chrzanowski, G. (1981). The genesis and nature of self estemm. American Journal of Psychotherapy, 35, 38-46.

Coopersmith, S. (1967). The antecedents of self-esteem. San Francisco: W. H. Freeman and Company.

Çuhadaroğlu, F. (1986). Self-esteem in adolescents. Unpublished Dissertation, Ankara: Hacettepe University.

Funder, D. C. (1997). The personality puzzle. New York: W. W. Norton $\&$ Company.

Gençöz, T. (2000). Positive and negative affect schedule: A study of validity and reliability. Turkish Journal of Psychology, 15, 19-28.

Kazarian, S. S., \& Martin, R. A. (2004). Humor styles, personality, and well-being among Lebanese university students. European Journal of Personality, 18, 209-219. doi:10.1002/per.505

Kuiper, N. A., \& Leite, C. (2010). Personality impressions associated with four distinct humor styles. Scandinavian Journal of Psychology, 51, 115-122. doi:10.1111/j.1467-9450.2009.00734.x

Kuiper, N. A., \& McHale, N. (2009). Humor styles as mediators between self-evaluative standards and psychological well-being. Journal of Psychology: Interdisciplinary and Applied, 143, 359-376. doi:10.3200/JRLP.143.4.359-376

Kuiper, N. A., \& Martin, R. A. (1998). Is sense of humor a positive personality characteristic? In W. Ruch (Ed.), The sense of humor: Explorations of a personality characteristic. Berlin: De Gruyter.

Kuiper, N. A., \& Martin, R. A. (1993). Humor and self-concept. International Journal of Humor Research, 6, 251-270. doi:10.1515/humr.1993.6.3.251

Martin, R. A. (2003). Sense of humor. In S. J. Lopez, \& C. R. Snyder (Eds.), Positive psychological assessment: A handbook of models and measures (pp. 313-326). Washington, DC: American Psychological Association. doi:10.1037/10612-020

Martin, R. A., Puhlik-Doris, P., Larsen, G., Gray, J., \& Weir, K. (2003). Individual differences in uses of humor and their relation to psychological well-being: Development of the Humor Styles Questionnaire. 


\section{Z. OZYESIL}

Journal of Research in Personality, 37, 48-75.

doi:10.1016/S0092-6566(02)00534-2

Martin, R. A. (2001). Humor, laughter and physical health: Methodological issues and research findings. Psychological Bulletin, 127, 504-519. doi:10.1037/0033-2909.127.4.504

Öner, N. (1996). The Manual of Piers Harris Children's Self-Concept Scale. Turkish Psychologists Association.

Pervin, A. L. (1993). Personality (theory and research). New York: John Wiley \& sons, Inc.

Saroglou, V., \& Scariot, C. (2002). Humor styles questionnaire: Personality and educational correlates in Belgian high school and college students. European Journal of Personality, 16, 43-54.

doi: $10.1002 /$ per.430

Satılmış, G., \& Seber, G. (1989). Self esteem in adolescents who live in training-institute. Journal of Psychology, 7, 68-73.
Watson, D., Clark, L. A., \& Tellegen, A. (1988). Development and validation of brief measures of positive and negative affect: The PANAS scales. Journal of Personality and Social Psychology, 54, 1063-1070. doi:10.1037/0022-3514.54.6.1063

Watson, D., Wiese, D., Vaidya, J., \& Tellegen, A. (1999). The two general activation systems of affect: Structural findings, evolutionary considerations, and psychobiological evidence. Journal of Personality and Social Psycholology, 76, 820-838.

Watson, D., \& Clark, L. A. (1984). Negative affectivity the disposition to experience aversive emotional states. Psychological Bulletin, 96, 465-490. doi:10.1037/0033-2909.96.3.465

Yerlikaya, E. (2003) A study on the adaptation of humor styles questionnaire. Unpublished Master Thesis, Adana: Cukurova University Institute of Social Sciences. 